\title{
Age effect on tree structure and biomass allocation in Scots pine (Pinus sylvestris L.) and Norway spruce (Picea abies [L.] Karst.)
}

\author{
Man $\mathrm{Hu}^{1,2}$ (D) Aleksi Lehtonen $^{3} \cdot$ Francesco Minunno $^{1,2} \cdot$ Annikki Mäkelä ${ }^{1,2}$
}

Received: 8 January 2020 / Accepted: 23 July 2020 / Published online: 11 September 2020

(C) The Author(s) 2020

\begin{abstract}
- Key message Tree structure equations derived from pipe model theory (PMT) are well-suited to estimate biomass allocation in Scots pine (Pinus sylvestris L.) and Norway spruce (Picea abies [L.] Karst.). However, age dependence of parameters should be accounted for when applying the equations.

- Context Pipe model theory-based (PMT-based) structure equations have been incorporated in many process-based models. However, more data concerning old-growth trees is needed to test the reliability and generality of the structure equations.

- Aims This study (1) tested the age independence of the PMT-based structure equations and (2) provided general information about the stability of tree structure with age.

- Methods A total of 162 Scots pine and 163 Norway spruce trees in four age groups were analysed to test the age effect on the parameters of structure equations using a linear mixed model. Biomass of stem, branch and foliage was estimated from destructive measurements, and with other tree dimensions, they were used to present the tree growth patterns.

- Results (1) Stem biomass proportion increased with age, while branch and foliage biomass proportion decreased; biomass allocation and most tree variables became steady after maturing. (2) PMT-based structure equations were well-suited to Scots pine and Norway spruce in all age groups; however, age dependence was detected in the parameters of these equations, except for the branch-related equations in Scots pine and stem form coefficient below the crown base in both species.

- Conclusion Our study (1) provides information applicable to predictions of growth and biomass allocation in old boreal stands and (2) suggests taking age effect into account when structure equations are implemented in forest growth models.
\end{abstract}

Keywords Scots pine $\cdot$ Norway spruce $\cdot$ Age effect $\cdot$ Pipe model parameters $\cdot$ Biomass proportion

Handling Editor: John M Lhotka

Contributions of the co-authors

$\mathrm{MH}$ performed the analysis and wrote the manuscript. AM conceived the idea and developed the methodology. AL contributed to data preparation and the methodology development. FM contributed to the interpretation and discussion of the results. All authors read, commented and approved the submission of the manuscript.

Man $\mathrm{Hu}$

man.hu@helsinki.fi

Aleksi Lehtonen

aleksi.lehtonen@luke.fi

Francesco Minunno

francesco.minunno@helsinki.fi

Annikki Mäkelä

annikki.makela@helsinki.fi
1 Department of Forest Sciences, University of Helsinki, P.O. Box 27, FI-00014 Helsinki, Finland

Institute for Atmospheric and Earth System Research (INAR) /Forest Sciences, FI-00014 Helsinki, Finland

3 Natural Resources Institute Finland (Luke), Latokartanonkaari 9, FI-00790 Helsinki, Finland 


\section{Introduction}

The target of forest management and planning today has changed from a strong focus on timber production to a broader objective of sustainability, such as increased carbon sequestration and the maintenance of biodiversity (Lämås and Fries 1995; Cintas et al. 2017; Triviño et al. 2017). This places new demands on management-oriented forest models: in order to assess the emerging management methods, they need to be applicable to the new types of stand created by these alternative management strategies. An important management modification intended for enhancing carbon sequestration is to increase the carbon storage in forest biomass by lengthening the rotation times of commercially managed forests (Busing and Garman 2002; Gustafson 2007). At the same time, there is an increasing need to estimate the carbon storage of protected old-growth forests in order to assess synergies of management for biodiversity and carbon sequestration (Luyssaert et al. 2008). In both cases, the models used in management planning need to expand to stands older than those previously evaluated against forestry data. In particular, carbon allocation patterns in old-growth stands have become essential, as carbon allocation is considered an important factor in predicting forest growth (Purves and Pacala 2008; Ise et al. 2010; Franklin et al. 2012).

To estimate tree biomass, management-oriented growth models usually apply individual-tree-based component biomass equations that are driven by dynamic variables calculated in the model, such as tree height, diameter, and crown height (Zianis et al. 2005). In empirical models, the biomass usually does not feed back into the growth model, but is calculated as a feedforward output (Repola 2009). In contrast, many processoriented models allocate primary production to new growth at each time step following assumptions on tree structure (Landsberg and Waring 1997; Lasch et al. 2005; Valentine and Mäkelä 2005). This means that the structural assumptions constitute feedback to subsequent growth through carbon allocation and are therefore crucial to the entire dynamics of the model. It is therefore essential that the structural assumptions are as stable as possible across different tree positions, stand structures and tree age.

In their seminal study, Shinozaki et al. (1964a, 1964b) introduced the pipe model theory (PMT) which has become widely used to describe stable structural relationships in trees. PMT postulates a proportional relationship between sapwood crosssectional area (CSA) at any height of the stem and foliage mass above this height. This implies that CSA at crown base is proportional to total tree foliage mass as well as the total CSA of branches in the crown. Combining the cross-sectional areas with tree height, crown length and mean branch length, using the concept of specific pipe length, further allows us to derive relationships between measurable tree dimensions and tree biomass components (Valentine 1985; Mäkelä 1986; Mäkelä 1997; Valentine and Mäkelä 2005). PMT-derived biomass equations have gained support from empirical studies in many tree species (Shelburne et al. 1993; Monserud and Marshall 1999; Berninger et al. 2005; Sattler and Comeau 2015).

The process-based growth model PREBAS (Mäkelä 1997; Valentine and Mäkelä 2005) calculates carbon allocation on the basis of PMT-based structure equations that relate the biomass of foliage, branch and stem of individual trees to easily measurable structure variables, such as diameter at breast height, tree height and crown ratio (the ratio of crown length to tree height). The parameters of these variables have been estimated for commercially important species in Fenno-Scandia in previous dedicated studies (Ilomäki et al. 2003; Berninger et al. 2005; Vanninen and Mäkelä 2005; Kantola and Mäkelä 2006; Mäkelä and Valentine 2006), where the assumptions were generally well-supported by the measurements. In addition, a recent model calibration study has provided evidence that the PREBAS model with the PMTbased structure equations is well-suited for simulating stand growth across Finland (Minunno et al. 2019). However, for the datasets both in the dedicated structural studies and in the model, calibration was largely confined to tree ages within normal commercial stand rotation. In order to apply the model to old-growth and other untypical stands, more data is needed to test the reliability of the structure equations.

To test the applicability of the PMT-based structure equations across a wide range of tree ages, we hypothesised that the parameters of the equations are species-specific and independent of tree age. The primary objectives of this study were (1) to provide, using this example, more general information about the growth patterns of tree structure with age; and (2) to test the age independence of the PMT-based structure equations in boreal Scots pine and Norway spruce with specific focus on old trees, and to modify the equations for age groups if required. The hypothesis was tested in 162 individual Scots pine and 163 Norway spruce trees from four age groups measured in Finland. The results will allow us to further develop models of carbon allocation in old trees (Mäkelä 1997; Minunno et al. 2019).

\section{Materials and methods}

\subsection{Study area and tree measurements}

Field data for this study was collected in 1988-1990 by the Finnish Forest Research Institute (now Natural Resources Institute Finland, Luke) (VAPU database) from southern Finland, with most of the sample stands (from the total of 52) located between latitude $60^{\circ}$ and $62^{\circ} \mathrm{N}$, and longitude $21^{\circ}$ and $30^{\circ} \mathrm{E}$. VAPU database consisted of a large number of destructive measurements of Scots pine and Norway spruce trees, and the sample trees were from different site types. Lehtonen et al. (2004a) have described the sampling design in more detail.

A total of 162 Scots pine trees (including 32 young, 72 middle-aged, 38 mature and 20 old trees) from stands dominated 
by Scots pine and 163 Norway spruce trees (including 12 young, 95 middle-aged, 37 mature and 19 old trees) from stands dominated by Norway spruce were included in the analysis. Because of the high variation of site types in VAPU database, we selected sample trees from the most common site types for each species to minimise the potential site-type effect on our hypothesis equations. In this study, all Scots pine trees came from site type 3 (mesic) and site type 4 (sub-xeric), while Norway spruce came from site type 2 (herb-rich heath) and site type 3 . Site types were characterised on the basis of their ground vegetation (Cajander 1949) (Appendix 1). The sample trees were classified into four age groups on the basis of conventional rotation length and growth traits through the trees' life stage (Meinzer et al. 2011): (1) young group $<26$ years, (2) middle-aged group $=26-$ 67 years, (3) mature group $=67-100$ years and (4) old group $>$ 100 years. Individual tree ages were determined by the ring number at breast height plus the additional years that tree needs to grow to the breast height. Additional years were determined with the consideration of tree species, site type and location (YliKojola and Ahola 1995).

This database includes destructive measurements of each sample tree. All sample trees were measured in the field for diameter at a series of relative heights along the stem (stump point, $1.3 \mathrm{~m}, 6 \mathrm{~m}$, crown base, and 1\%, 2.5\%, 5\%, 7.5\%, 15\%, $10-90 \%$ with $10 \%$ intervals, $85 \%$ and $95 \%$ of tree height), diameter at branch base, height of the crown base and height of each branch (Hu et al. 2020). Crown base was recorded as the height of the lowest branch, and only one dead whorl above was allowed. Regarding branch sampling, for Norway spruce with height $\leq 10 \mathrm{~m}$ and all the Scots pine, diameter (above the basal swelling) and height of each branch were measured. For Norway spruce with height $>10 \mathrm{~m}$, branch height and diameter were measured for all branches every second metre from the treetop. For each sample tree, sample branches were picked randomly from each tenth of the crown length. Branch length and cross diameter at branch base were measured, and the sample branches were first put into paper bags and later packed in larger black plastic bags. The sample branches were then taken to the laboratory to determine the branch and foliage mass. In the laboratory, sample branches of Scots pine were dried in paper bags at $105^{\circ} \mathrm{C}$ for $48 \mathrm{~h}$ and those of Norway spruce at $75^{\circ} \mathrm{C}$ for $48 \mathrm{~h}$. Foliage was separated from branches after drying. Dry mass of branch wood and foliage on the sample branches were determined separately.

\subsection{Component biomass calculation}

The stem biomass for each sample tree was calculated by multiplying the stem volume and stem wood density. Stem volume (above bark) was estimated by fitting a spline curve using the diameter measurements along the stem. Empirical values were used for the stem wood density (Vanninen and Mäkelä 2000; Horáček et al. 2017). In addition, stem biomasses inside the crown and below the crown base were calculated separately by setting the crown base height while calculating the integral of the spline curve.

We used previously calculated estimates for whole-tree live branch wood (Lehtonen et al. 2004b) and foliage biomass (Lehtonen 2005) of each sample tree. In those studies, the whole-tree biomasses were obtained by up-scaling from sample branches to the tree level with a mixed linear model. For calculating branch biomass, an individual branch biomass model based on branch diameter was applied to all the branches. Needle biomass of each branch was estimated on the basis of branch diameter and relative height of the branch in the canopy (Lehtonen et al. 2004a; Lehtonen 2005). Details of the method are provided in Appendix 2.

\subsection{Hypothesis equations description}

We evaluated structure equations derived from PMT, as presented by Mäkelä (1997) and Kantola and Mäkelä (2006). Firstly, foliage dry biomass $W_{f}(\mathrm{~kg})$ is assumed to be proportional to stem CSA at crown base, $A_{c}\left(\mathrm{~m}^{2}\right)$ :

$W_{f}=\eta_{s} A_{c}$

where $\eta_{s}$ is an empirical coefficient. Secondly, the total crosssectional area of live branches, $A_{b}\left(\mathrm{~m}^{2}\right)$, is also assumed to be proportional to $A_{c}$ :

$A_{b}=\eta_{s} / \eta_{b} A_{c}$

where $\eta_{b}$ is an empirical coefficient relating $W_{f}$ to $A_{b}$.

If we denote the basal-area-weighted average branch length by $H_{b}(\mathrm{~m})$, branch wood dry biomass $W_{b}(\mathrm{~kg})$ can be expressed as:

$W_{b}=\rho_{b} \varphi_{b} H_{b} A_{b}$

where $\rho_{b}$ is branch wood density and $\varphi_{b}$ is an empirical form coefficient. Furthermore, we assume that $H_{b}$ is a power function of crown length, $H_{c}(\mathrm{~m})$ :

$H_{b}=\gamma_{b} H_{c}^{b}$

where $\gamma_{b}$ and $b$ are empirical parameters. Using (2) and (4), $W_{b}$ can be estimated from $H_{c}$ and $A_{c}$ :

$W_{b}=\rho_{b} \varphi_{b} \gamma_{b} H_{c}^{b} \eta_{s} / \eta_{b} A_{c}$

If we denote the stem dry biomass by $W_{\text {stem }}(\mathrm{kg})$, it can be expressed as:

$W_{\text {stem }}=W_{c}+W_{s}$

where $W_{c}$ and $W_{s}$ are stem dry biomass above and below the crown base, respectively. The $W_{\text {stem }}$ can be calculated by multiplying the stem volume and stem wood density, $\rho_{s}$. Thus, the 
stem volume above, $V_{c}\left(\mathrm{~m}^{3}\right)$, and below the crown base, $V_{s}\left(\mathrm{~m}^{3}\right)$, can be related to $H_{c}, H_{s}(\mathrm{~m})$ (crown base height), and $A_{c}$ as follows:

$V_{c}=\varphi_{c} A_{c} H_{c}$

$V_{s}=\varphi_{s} A_{c} H_{s}$

where $\varphi_{c}$ and $\varphi_{s}$ are empirical form coefficients of the stem above and below the crown base. $\varphi_{s}$ depends on the crown ratio $r\left(H_{C} / H\right)$ as $\varphi_{s}=(1+r) / 2 r$ and the latter is based on the assumptions that the stem below the crown base is a cut cone with top surface $A_{c}$ and base surface $A_{c} / r$ (Valentine et al. 1994). Note that the form coefficients are defined with reference to $A_{c}$, so empirically $\varphi_{s} \geq 1$ and $\varphi_{c}<1$. Using the equations above, the total aboveground dry biomass of the tree, $W_{a b}(\mathrm{~kg})$ can be written as:

$W_{a b}=H_{c} A_{c}\left[\eta_{s} / H_{c}+\frac{\rho_{b} \varphi_{b} \gamma_{b} H_{c}^{b-1} \eta_{s}}{\eta_{b}}+\frac{\rho_{s} \varphi_{s}(1-\mathrm{r})}{\mathrm{r}}+\rho_{s} \varphi_{c}\right]$

The components in parentheses, from left to right, represent the contributions of the foliage, the branches, the stem below the crown base and the stem inside the crown to total aboveground biomass.

\subsection{Statistical analysis}

Data analyses were conducted with SPSS Statistics (IBM, 1994 2019) and the R statistical software (Team 2017). For objective (1), we used analysis of variance (ANOVA) to compare tree height, crown length, crown ratio and dry biomass components from different age groups to determine the effect of age on the tree structure. The measurement data was first checked for normality using the Shapiro-Wilk test (Shapiro and Wilk 1965), and then the means were compared using the least significant difference (LSD) test (Williams and Abdi 2010). Kruskal-Wallis oneway ANOVA (Lin and Haseman 1978) was applied to compare distributions across groups if the data were not normally distributed. Furthermore, we analysed the linear relationships between the dependent and independent variables in each hypothesis equation with linear regression, in the whole dataset. Moreover, we ln-transformed Eq. (4) and analysed the transformed linear regression.

For objective (2), linear mixed-effect models (LMEM) and likelihood-ratio tests (LRT) were used to analyse the age effect on each hypothesis equation. For this approach, we applied the Imer function in $\mathrm{R}$ from the lme4 package (Bates et al. 2014). Furthermore, the possible age effect on the slope parameters of hypothesis equations were tested between four age groups using restricted maximum likelihood (REML) approach (McGilchrist and Yau 1995). Because of the focus on old trees, old group was used as the reference level for each model. Similarity of the slope parameters between each group with the reference was defined to
Table 1 Independent $\left(x^{k}\right)$ and dependent $\left(y^{k}\right)$ variables in models [10]. $k$ is the hypothesis equation number. Notation: stem cross-sectional area at crown base $\left(A_{c}\right)$, foliage biomass $\left(W_{f}\right)$, total cross-sectional area of live branches $\left(A_{b}\right)$, branch wood density $\left(\rho_{b}\right)$, basal-area-weighted average branch length $\left(H_{b}\right)$, branch biomass $\left(W_{b}\right)$, crown length $\left(H_{c}\right)$, stem volume above $\left(V_{c}\right)$ and below the crown base $\left(V_{s}\right)$, crown ratio $(r)$ and stem from coefficient below the crown base $\left(\varphi_{s}\right)$

\begin{tabular}{lllllll}
\hline$k$ & 1 & 2 & 3 & $4^{\mathrm{a}}$ & 7 & $8^{\mathrm{b}}$ \\
\hline$x^{k}$ & $A_{c}$ & $A_{c}$ & $\rho_{b} H_{b} A_{b}$ & $\ln H_{c}$ & $H_{c} A_{c}$ & $(1+r) / 2 r$ \\
$y^{k}$ & $W_{f}$ & $A_{b}$ & $W_{b}$ & $\ln H_{b}$ & $V_{c}$ & $\varphi_{s}$ \\
\hline
\end{tabular}

a Eq. (4) was ln-transformed

$\mathrm{b} \varphi_{s}$ is a free parameter that depends on crown ratio, instead of a constant value estimated by $V_{s} / H_{s} A_{c}$. Hence, we hypothesised $V_{s}=(1+r) /$ $2 r\left(H_{s} A_{c}\right)$ and tested the age independence on $\varphi_{s}=(1+r) / 2 r$

be significant at the level of $p<0.05$. The slope parameters of each age group were estimated using the mixed-effect model as follows:

$y_{j i}^{k}=\beta_{0}^{k}+\left(\beta_{1}^{k}+\beta_{a}^{k}\right) x_{j i}^{k}+\mu_{j}^{k}+\varepsilon_{j i}^{k}$

where $y^{k}$ and $x^{k}$ denote the dependent and independent variables indexed with $k$ (Table 1 ), $j$ is plot, $i$ is measurement, $\beta_{0}^{k}$ and $\beta_{1}^{k}$ are parameters, $\beta_{a}^{k}$ is modification of the slope parameter $\beta_{1}^{k}$ in age group $a, \mu_{j}^{k}$ is the random effect based on plots, and $\varepsilon_{j i}^{k}$ is the residual of the model. An intercept $\beta_{0}^{k}$ in the linear relationship was considered because in the original pipe model theory, the ratio of $W_{f}$ to cross-sectional area of sapwood at crown base is constant; however, we used the total cross-sectional area at crown base (over bark measurements) as a proxy for sapwood. It should be mentioned that LMEM and LRT approach were also applied to test the site-type effects before proceeding to the age-independence test to avoid interaction.

\section{Results}

\subsection{Age effect on aboveground biomass allocation and tree growth}

Biomass of each tree component (stem, branch, foliage) increased with growing age in both Scots pine and Norway spruce. The corresponding values in old group were significantly higher than those in the younger groups except that foliage biomass in the old group was not significantly larger than that of the mature group (Table 2). As expected, stem biomass was the main aboveground biomass pool in all age groups. The proportion of stem in the total aboveground biomass increased significantly with increasing age (Scots pine: $n=162, F=315.6, p<0.05$; Norway spruce: $n=163, F=86.31, p<0.05$ ), while the branch and foliage biomass showed the opposite pattern (Branch: Scots pine: 
Table 2 Mean value and standard error of aboveground, stem, foliage and branch biomass ( $W_{\mathrm{ab}}, W_{\text {stem }}, W_{f}, W_{b}$, respectively), tree height $(H)$, crown length $\left(H_{c}\right)$, basal area weighted mean branch length $\left(H_{b}\right)$, crown ratio $(r)$ and slenderness $(H / D)$ by age groups, and their $F$ and $p$ values.
Significant difference $(p<0.05)$ from one to another is marked by the letters $\mathrm{a}, \mathrm{b}$ and $\mathrm{c}$. Values following each species are the sample number in each age group

\begin{tabular}{|c|c|c|c|c|c|c|c|c|c|c|c|}
\hline Factor & Unit & $F$ & $p$ & Young & & Middle-aged & & Mature & & Old & \\
\hline \multicolumn{2}{|c|}{ Scots pine } & & & 32 & & 72 & & 38 & & 20 & \\
\hline$H$ & $\mathrm{~m}$ & 43.30 & $<0.05$ & $5.17 \pm 0.25$ & $\mathrm{c}$ & $10.48 \pm 0.40$ & $\mathrm{~b}$ & $17.32 \pm 0.58$ & $\mathrm{a}$ & $20.48 \pm 0.61$ & $\mathrm{a}$ \\
\hline$H_{c}$ & $\mathrm{~m}$ & 61.51 & $<0.05$ & $3.74 \pm 0.13$ & $\mathrm{c}$ & $5.60 \pm 0.20$ & $\mathrm{~b}$ & $7.94 \pm 0.39$ & $\mathrm{a}$ & $9.73 \pm 0.34$ & $\mathrm{a}$ \\
\hline$H_{b}$ & $\mathrm{~m}$ & 40.55 & $<0.05$ & $1.10 \pm 0.04$ & $\mathrm{c}$ & $1.35 \pm 0.05$ & $\mathrm{c}$ & $1.85 \pm 0.08$ & $\mathrm{~b}$ & $2.47 \pm 0.17$ & $\mathrm{a}$ \\
\hline$r$ & l & 35.21 & $<0.05$ & $0.75 \pm 0.55$ & $\mathrm{a}$ & $0.55 \pm 0.02$ & $\mathrm{~b}$ & $0.45 \pm 0.47$ & $\mathrm{c}$ & $0.47 \pm 0.02$ & $\mathrm{bc}$ \\
\hline$H / D$ & l & 14.68 & $<0.05$ & $66.77 \pm 2.33$ & $\mathrm{bc}$ & $88.91 \pm 2.37$ & $\mathrm{a}$ & $81.78 \pm 2.32$ & $a b$ & $71.85 \pm 3.10$ & $\mathrm{~b}$ \\
\hline$W_{\mathrm{ab}}$ & $\mathrm{kg}$ & 94.36 & $<0.05$ & $16.14 \pm 1.75$ & $\mathrm{c}$ & $57.01 \pm 6.54$ & $\mathrm{c}$ & $211.75 \pm 20.38$ & $\mathrm{~b}$ & $392.90 \pm 38.09$ & $\mathrm{a}$ \\
\hline$W_{\text {stem }}$ & $\mathrm{kg}$ & 94.82 & $<0.05$ & $5.47 \pm 0.65$ & $\mathrm{c}$ & $30.15 \pm 3.76$ & $\mathrm{c}$ & $138.09 \pm 14.98$ & $\mathrm{~b}$ & $250.20 \pm 23.05$ & $\mathrm{a}$ \\
\hline$W_{f}$ & $\mathrm{~kg}$ & 39.12 & $<0.05$ & $2.69 \pm 0.25$ & $\mathrm{~b}$ & $4.64 \pm 0.42$ & $\mathrm{~b}$ & $9.76 \pm 0.70$ & $\mathrm{a}$ & $12.53 \pm 1.43$ & $\mathrm{a}$ \\
\hline$W_{b}$ & $\mathrm{~kg}$ & 55.14 & $<0.05$ & $6.48 \pm 0.76$ & $\mathrm{c}$ & $16.49 \pm 1.97$ & $\mathrm{c}$ & $41.71 \pm 3.86$ & $\mathrm{~b}$ & $83.15 \pm 11.07$ & $\mathrm{a}$ \\
\hline \multicolumn{3}{|c|}{ Norway spruce } & & \multicolumn{2}{|l|}{12} & \multicolumn{2}{|l|}{95} & \multicolumn{2}{|l|}{37} & \multicolumn{2}{|l|}{19} \\
\hline$H$ & $\mathrm{~m}$ & 38.53 & $<0.05$ & $8.29 \pm 1.64$ & $\mathrm{c}$ & $13.18 \pm 0.47$ & $\mathrm{~b}$ & $19.93 \pm 0.91$ & $\mathrm{a}$ & $22.70 \pm 1.11$ & $\mathrm{a}$ \\
\hline$H_{c}$ & $\mathrm{~m}$ & 21.70 & $<0.05$ & $7.25 \pm 1.26$ & $\mathrm{~b}$ & $10.42 \pm 0.41$ & $\mathrm{~b}$ & $14.28 \pm 0.71$ & $\mathrm{a}$ & $16.97 \pm 1.13$ & $\mathrm{a}$ \\
\hline$H_{b}$ & $\mathrm{~m}$ & 18.13 & $<0.05$ & $1.10 \pm 0.14$ & $\mathrm{~b}$ & $1.39 \pm 0.04$ & $\mathrm{~b}$ & $1.99 \pm 0.14$ & $\mathrm{a}$ & $2.11 \pm 0.10$ & $\mathrm{a}$ \\
\hline$r$ & I & 8.01 & $<0.05$ & $0.89 \pm 0.01$ & $\mathrm{a}$ & $0.79 \pm 0.01$ & $\mathrm{~b}$ & $0.72 \pm 0.02$ & $\mathrm{c}$ & $0.74 \pm 0.02$ & $\mathrm{bc}$ \\
\hline$H / D$ & l & 2.15 & $>0.05$ & $83.94 \pm 3.77$ & $\mathrm{a}$ & $90.48 \pm 1.62$ & $\mathrm{a}$ & $86.68 \pm 2.03$ & $\mathrm{a}$ & $82.59 \pm 3.16$ & $\mathrm{a}$ \\
\hline$W_{\mathrm{ab}}$ & $\mathrm{kg}$ & 32.20 & $<0.05$ & $59.88 \pm 38.98$ & $\mathrm{c}$ & $98.52 \pm 11.09$ & $\mathrm{c}$ & $240.93 \pm 25.14$ & $\mathrm{~b}$ & $432.18 \pm 62.89$ & $\mathrm{a}$ \\
\hline$W_{\text {stem }}$ & $\mathrm{kg}$ & 39.98 & $<0.05$ & $35.85 \pm 26.72$ & $\mathrm{c}$ & $61.68 \pm 6.98$ & $\mathrm{c}$ & $174.92 \pm 18.92$ & $\mathrm{~b}$ & $326.68 \pm 47.03$ & $\mathrm{a}$ \\
\hline$W_{f}$ & $\mathrm{~kg}$ & 9.07 & $<0.05$ & $10.96 \pm 5.42$ & $\mathrm{~b}$ & $17.20 \pm 1.94$ & $\mathrm{~b}$ & $27.79 \pm 2.97$ & $\mathrm{a}$ & $39.90 \pm 6.53$ & $\mathrm{a}$ \\
\hline$W_{b}$ & $\mathrm{~kg}$ & 16.56 & $<0.05$ & $13.06 \pm 7.03$ & $\mathrm{c}$ & $19.69 \pm 2.43$ & $\mathrm{c}$ & $38.21 \pm 4.06$ & $\mathrm{~b}$ & $65.59 \pm 11.58$ & $\mathrm{a}$ \\
\hline
\end{tabular}

$n=162, F=189.1, p<0.05$; Norway spruce: $n=163, F=48.24$, $p<0.05$; foliage: Scots pine: $n=162, F=244.1, p<0.05$; Norway spruce: $n=163, F=95.27, p<0.05$ ) (Fig. 1).
For tree structure development, tree height, crown length, crown width and crown ratio varied between the age groups; however, the development patterns of those variables were not

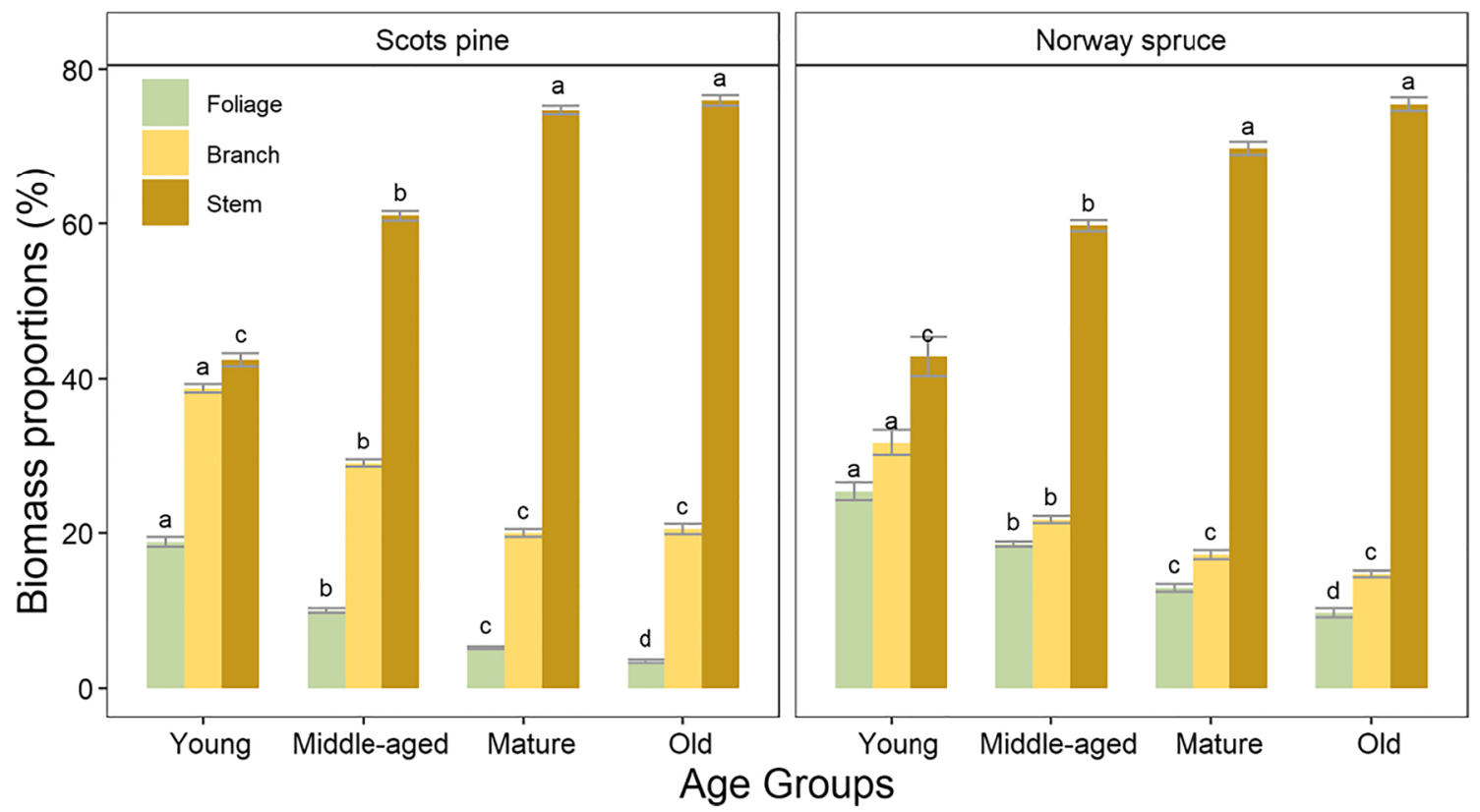

Fig. 1 Biomass proportion (\%) of each aboveground component (stem, branch and foliage) at different age groups in Scots pine and Norway spruce. Error bars indicate the standard errors. Different letters indicate significant differences among different age groups for each component $(p<0.05)$ 
all the same in Scots pine and Norway spruce with growing age. For both species, tree height $(H)$, crown length $\left(H_{C}\right)$ and crown width (indicated by $H_{b}$ ) were significantly longer in the mature and old stands relative to the younger stands, but with little difference between the mature and old groups for $H$ and $H_{C}$. In Scots pine, $H_{b}$ was also found statistically significantly larger in the old group than that in the mature group (Table 2). Crown ratio was largest in the young group and decreased with age; however, the difference was not significant between mature and old group in both species (Table 2). Moreover, the proportion of stem biomass decreased with increasing crown ratio, while the proportion of branch and foliage increased (Fig. 2). The proportion of foliage and branch biomass (from total aboveground biomass) decreased with growing crown length while that of stem biomass increased (Fig. 3).

\subsection{Age effect on hypothesis equations}

LRT results indicated that (1) no site-type effect was detected on the hypothesis equations (Table 9 in Appendix 2); (2) significant age effect was detected on all the relationship in Norway spruce except for the relationship between $\varphi_{s}$ and $(1+r) / 2 r$ (Eq. 8). In Scots pine, age effect was found only on the relationships: $W_{f} \sim A_{c}$ (Eq. 1) and $V_{c} \sim H_{c} A_{c}$ (Eq. 7), while no age dependence was detected on the branch-related equations (Eqs. 2, 3, and 4) and $\varphi_{s}$ estimate equation (Eq. 8) (Table 3). Nevertheless, linear regression analysis results showed that across the whole dataset, the dependence and independence variables of each hypothesis equation showed high $R^{2}$ values, which indicates a strong relationship (Table 4). All the mean structure parameters in Eqs. (1)-(9) are shown in Table 5.

\subsection{Slope parameters estimate and age-independence test}

The REML approach demonstrated the age-specific parameters in the hypothesis equations. For Norway spruce, all parameters in the old group proved to differ from the younger groups except for the stem form coefficient below the crown base $\varphi_{s}$ (Table $6, k=$ 8). However, for Scots pine, age dependence was detected only

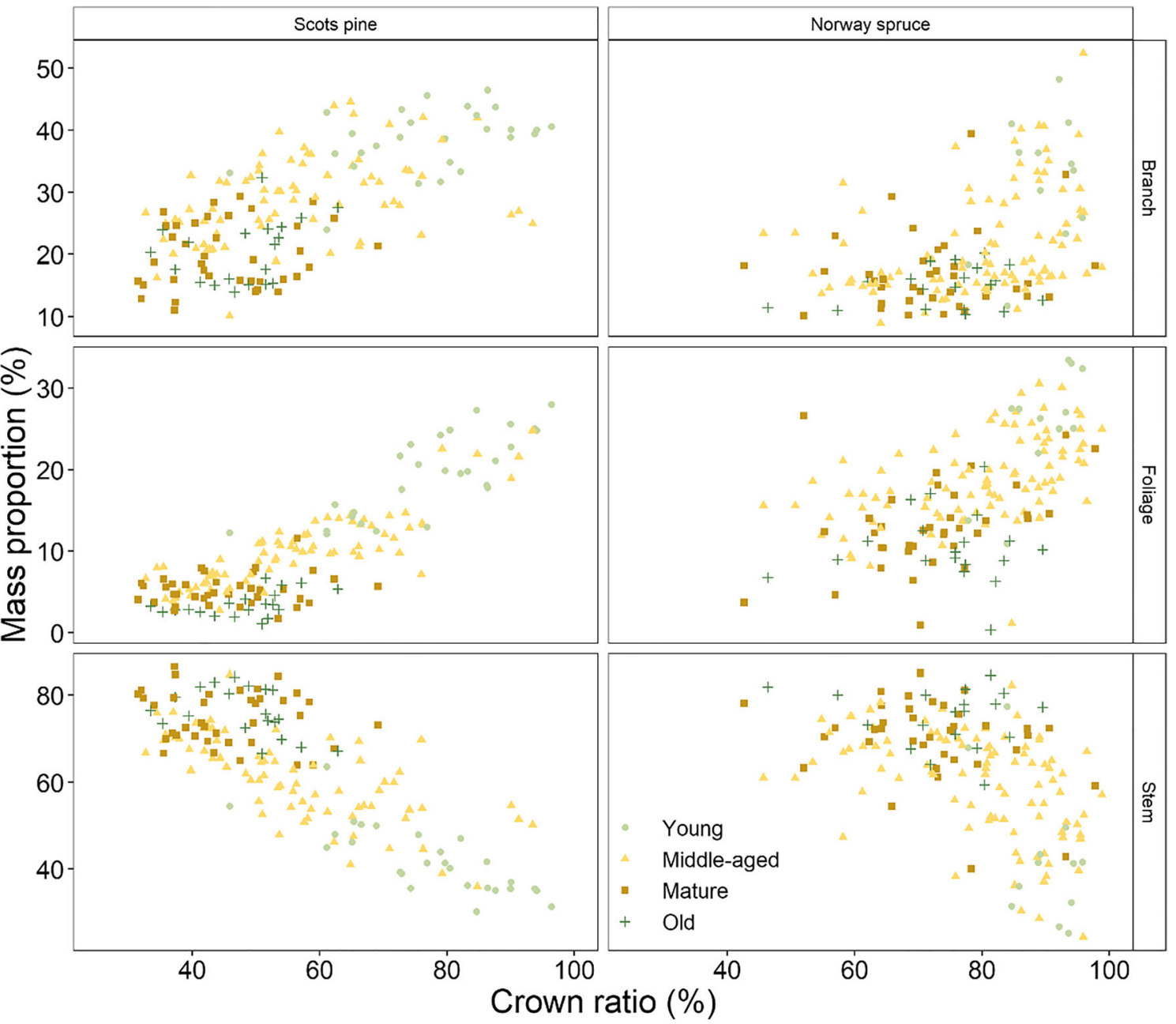

Fig. 2 Biomass proportions (\%) of each aboveground component (stem, branch and foliage) in the whole tree as a function of crown ratio (\%) in Scots pine and Norway spruce 


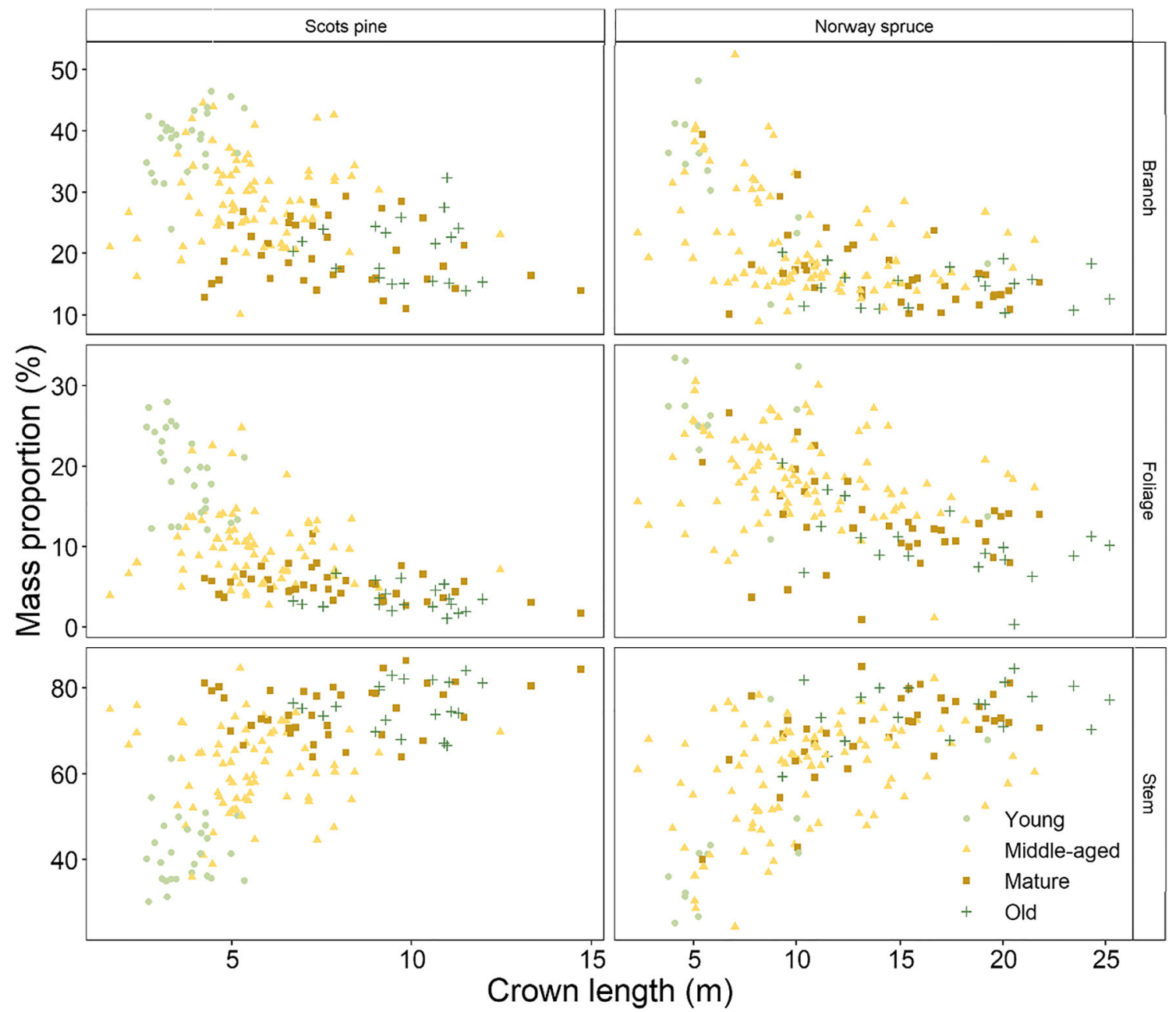

Fig. 3 Biomass proportions (\%) of each aboveground component (stem, branch and foliage) as a function of crown length (m) in Scots pine and Norway spruce

Table 3 Effect of age on hypothesis equations in Scots pine and Norway spruce. The $p$ values and chi square $\left(\chi^{2}\right)$ are listed. The $p$ values with grey background are statistically significant $(p<0.05)$ based on LRT approach, which means age has a significant effect on the corresponding hypothesis equation

\begin{tabular}{cccccc}
\hline$x^{k}$ & $y^{k}$ & \multicolumn{2}{c}{ Scots pine $(162)$} & \multicolumn{2}{c}{ Norway spruce $(163)$} \\
\hline$A_{c}$ & $W_{f}$ & 0.020 & 9.831 & 0.002 & 14.312 \\
$A_{c}$ & $A_{b}$ & 0.919 & 0.499 & 0.000 & 27.489 \\
$\rho_{b} H_{b} A_{b}$ & $W_{b}$ & 0.322 & 3.484 & 0.000 & 28.785 \\
$\ln H_{c}$ & $\ln H_{b}$ & 0.192 & 4.734 & 0.044 & 8.093 \\
$H_{c} A_{c}$ & $V_{c}$ & 0.013 & 10.739 & 0.013 & 10.677 \\
$(1+r) / 2 r$ & $\varphi_{s}$ & 0.070 & 8.784 & 0.297 & 3.683 \\
\hline
\end{tabular}


Table 4 For each hypothesis equation, the $p$ values, root mean square error (RMSE) and $R^{2}$ between the dependent and independent variables are given. The number of samples is shown in parentheses

\begin{tabular}{|c|c|c|c|c|c|c|}
\hline \multirow[t]{2}{*}{ Equations } & \multicolumn{3}{|c|}{ Scots pine (162) } & \multicolumn{3}{|c|}{ Norway spruce (163) } \\
\hline & $p$ & RMSE & $R^{2}$ & $p$ & RMSE & $R^{2}$ \\
\hline$W_{f}=\eta_{s} A_{c}$ & $<0.05$ & 7.78 & 0.694 & $<0.05$ & 28.91 & 0.789 \\
\hline$A_{b}=\eta_{s} / \eta_{b} A_{c}$ & $<0.05$ & 0.01 & 0.765 & $<0.05$ & 0.02 & 0.880 \\
\hline$W_{b}=\rho_{b} \varphi_{b} H_{b} A_{b}$ & $<0.05$ & 8.69 & 0.886 & $<0.05$ & 36.61 & 0.900 \\
\hline $\ln \left(H_{b}\right)=b \ln \left(H_{c}\right)+\ln \left(\gamma_{b}\right)$ & $<0.05$ & 1.39 & 0.661 & $<0.05$ & 1.98 & 0.629 \\
\hline$V_{c}=\varphi_{c} H_{c} A_{c}$ & $<0.05$ & 0.11 & 0.988 & $<0.05$ & 0.38 & 0.976 \\
\hline$\varphi_{s}=(1+\mathrm{r}) / 2 \mathrm{r}$ & $<0.05$ & 0.03 & 0.987 & $<0.05$ & 0.13 & 0.979 \\
\hline
\end{tabular}

in stem form coefficient above the crown $\varphi_{c}$ (Table 6, $k=7$ ) and the parameter $\eta_{s}$ (ratio between $W_{f}$ and CSA) (Table $6, k=1$ ). No significant age effect was detected on the slope parameters in branch-related equations (Table $6, k=2-4$ ) and the stem form coefficient below the crown base $\varphi_{s}$ (Table $6, k=8$ ) (old group as the reference).

In Scots pine, trees in the middle-aged or mature groups had significantly larger foliage biomass than those in the old group with a given $A_{c}$ (Table $6, k=1$, Fig. 4). The stem form coefficient above the crown base $\varphi_{c}$ was significantly smaller in the old than that that in the mature group (Table $6, k=7$ ), while no significant difference was detected between the old and young or middleaged group.

In Norway spruce, results showed that $W_{f}$ differed between age groups with a given $A_{c}$. Trees in the old group had smaller foliage biomass than those in the young or middle-aged group with a given $A_{c}$ (Table $6, k=1$, Fig. 4). Similarly, $W_{b}$ differed between age groups with a given $H_{b} A_{b}$, the old group showing smaller branch biomass than other groups with a given $H_{b} A_{b}$ (Table $6, k=3$ ). The slope parameter between $A_{b}$ and $A_{c}$ differed between the old and all other groups. It showed that Norway spruce trees in the old group had larger total branch basal area than those in the other age groups for a given $A_{c}$ (Table 6, $k=2$,

Table 5 Mean structure parameter values and standard errors in hypothesis equations. Note that $\rho_{s}$ and $\rho_{b}$ were not measured, and the values used were based on literature

\begin{tabular}{llll}
\hline Parameter & Scots pine & Norway spruce & Equation \\
\hline$\eta_{s}$ & $369.10 \pm 17.77$ & $812.60 \pm 33.11$ & $(1)$ \\
$\eta_{s} / \eta_{b}$ & $1.65 \pm 0.07$ & $1.58 \pm 0.05$ & $(2)$ \\
$\varphi_{b}$ & $1.16 \pm 0.03$ & $0.49 \pm 0.01$ & $(3)$ \\
$\gamma_{b}$ & $0.34 \pm 0.08$ & $0.32 \pm 0.09$ & $(4)$ \\
$b$ & $0.83 \pm 0.04$ & $0.64 \pm 0.04$ & $(4)$ \\
$\varphi_{c}$ & $0.39 \pm 0.00$ & $0.42 \pm 0.01$ & $(7)$ \\
$\varphi_{s}$ & $1.61 \pm 0.02$ & $1.32 \pm 0.01$ & $(8)$ \\
$\rho_{b}$ & 400 & 590 & $(3),(5)$ \\
$\rho_{s}$ & 398 & 351 & $(9)$ \\
\hline
\end{tabular}

Fig. 5). The slope parameter between $\ln \left(H_{b}\right)$ and $\ln \left(H_{c}\right)$ in the old group was larger than in the other age groups, showing that, with the same crown length, trees in the old group tended to have longer branches than those in young or middle-aged groups (Table $6, k=4$, Fig. 6 ). In addition, $\varphi_{c}$ was significantly larger in the old than in the middle-aged or mature groups (Table $6, k=$ 7 ), while $\varphi_{s}$ (Table $6, k=8$ ) was found to be age-independent.

\section{Discussion}

This study is, to our knowledge, the first that has focused on the possible age dependence of PMT-based tree structure equations. Our main results were that (1) on average, the hypothesis structure equations were well-suited for boreal Scots pine and Norway spruce, but (2) in a closer look, age dependence was detected in many of the PMT parameters studied, and more so in Norway spruce than in Scots pine. In Scots pine, old trees had a tendency of developing a stronger taper of stem inside the crown and had less foliage than younger trees with the same cross-sectional area at the crown base. In contrast, old Norway spruce trees tended to develop less tapering of stem inside the crown, but they also had less foliage biomass than expected on the basis of parameters from younger trees. In addition, they had relatively more branch cross-sectional area than expected on the basis of younger trees. In both species, stem form coefficient below the crown base followed a prescribed dependence on crown ratio rather than tree age. The results provide information applicable to predictions of growth, biomass and carbon allocation in old boreal stands.

In this study, Scots pine and Norway spruce trees were selected from two of the most common site types, respectively. Earlier studies (Berninger et al. 2005; Lehtonen 2005) suggest that site type could affect tree biomass and the pipe model ratio because site fertility might be related to the physiological activity of the foliage relative to the transport capacity of sapwood. Recently, Lehtonen et al. (2019) found that Scots pine in site type 3 (mesic) had larger ratio of foliage biomass to crown basal area than in other site types in a large 


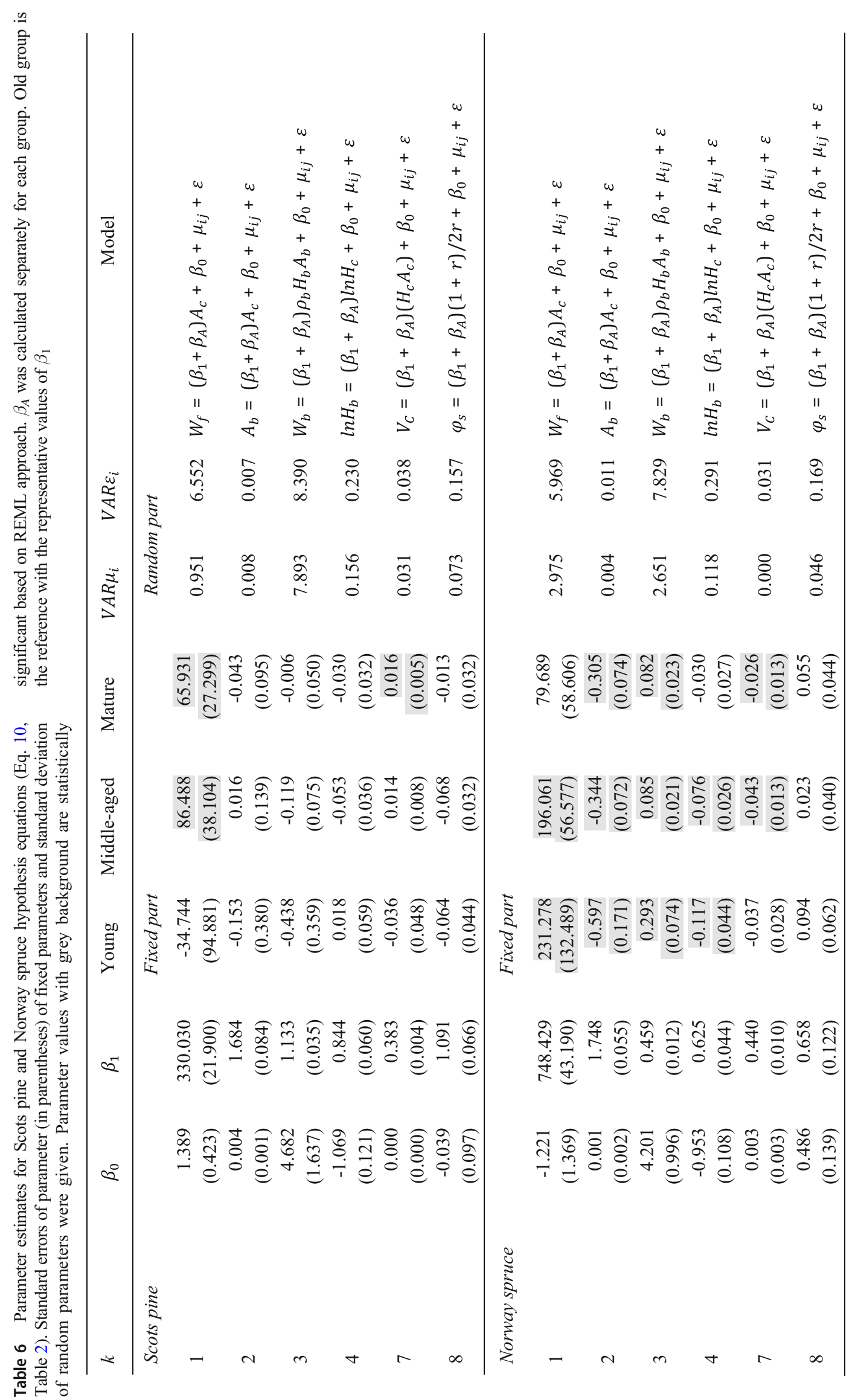

INRAC פspringer 


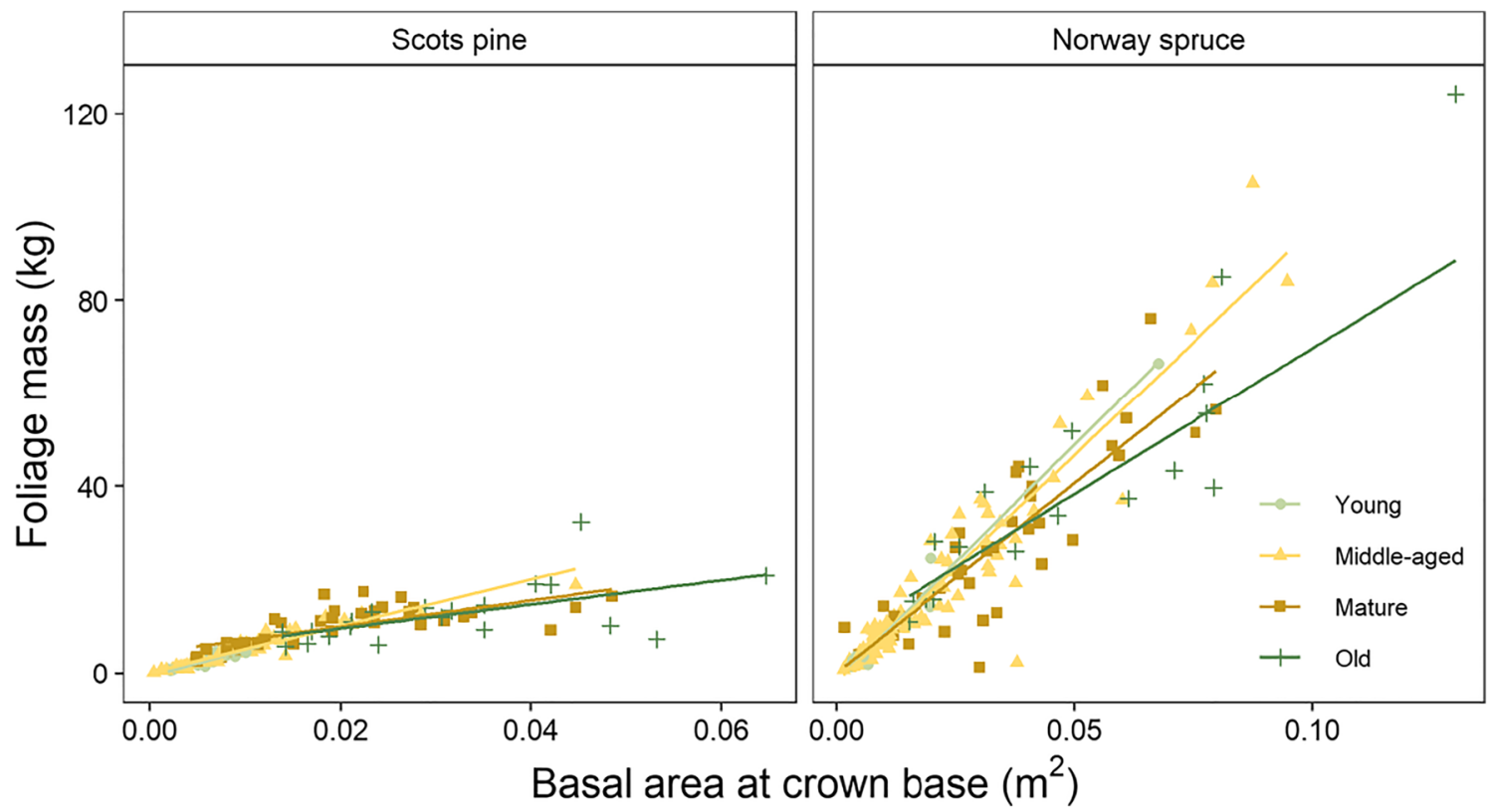

Fig. 4 Foliage biomass $(\mathrm{kg})$ as a function of basal area at crown base $\left(\mathrm{m}^{2}\right)$ in Scots pine and Norway spruce

dataset collected from Finland and Sweden, while in Norway spruce, differences in the ratios between the site types were relatively small. To explore the possibility of significant site effects in our data, we applied the LMEM and LRT approach to testing the site-type effect before proceeding to the age-independence test of the hypothesis equations. However, although aboveground biomass was significantly different between site types, no site-type effect was detected on the relationship between $W_{f}$ and CSA in this study for either species, neither was it detected for the other equations
(Table 9 in Appendix 2). In previous studies, Inagaki et al. (2019) found that the effect of site types was not significant on foliage and branch biomass per unit basal area at crown base; Medhurst et al. (1999) reported that the relationship between leaf area and sapwood area in Eucalyptus nitens was site-independent. Other studies that have detected significant differences between site types have included much wider datasets with respect to site type (Berninger et al. 2005; Lehtonen et al. 2019). We therefore considered it justified, based on the insignificant site-type effect on the hypothesis

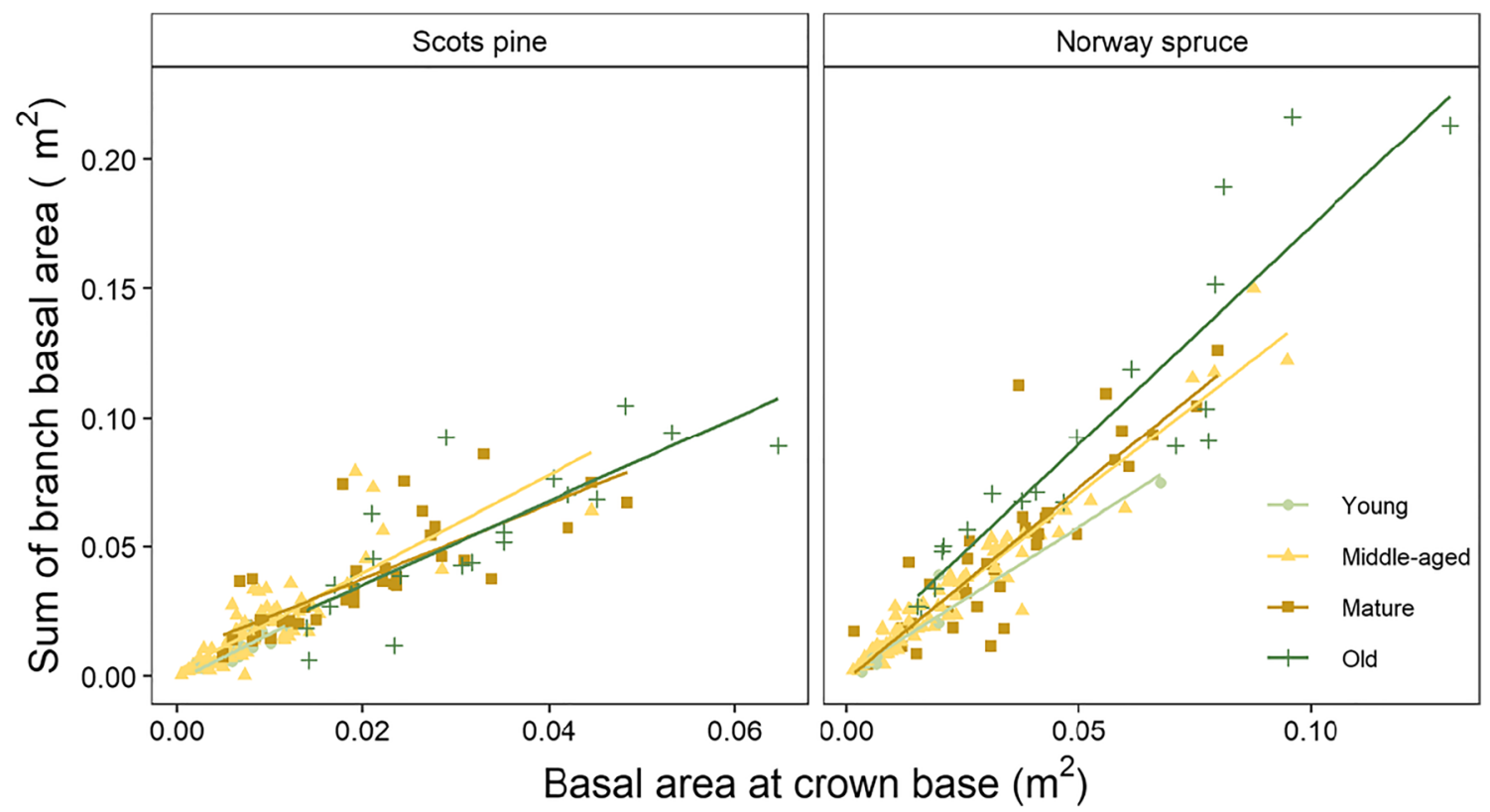

Fig. 5 Sum of branch basal area $\left(\mathrm{m}^{2}\right)$ as a function of basal area at crown base $\left(\mathrm{m}^{2}\right)$ in Scots pine and Norway spruce 


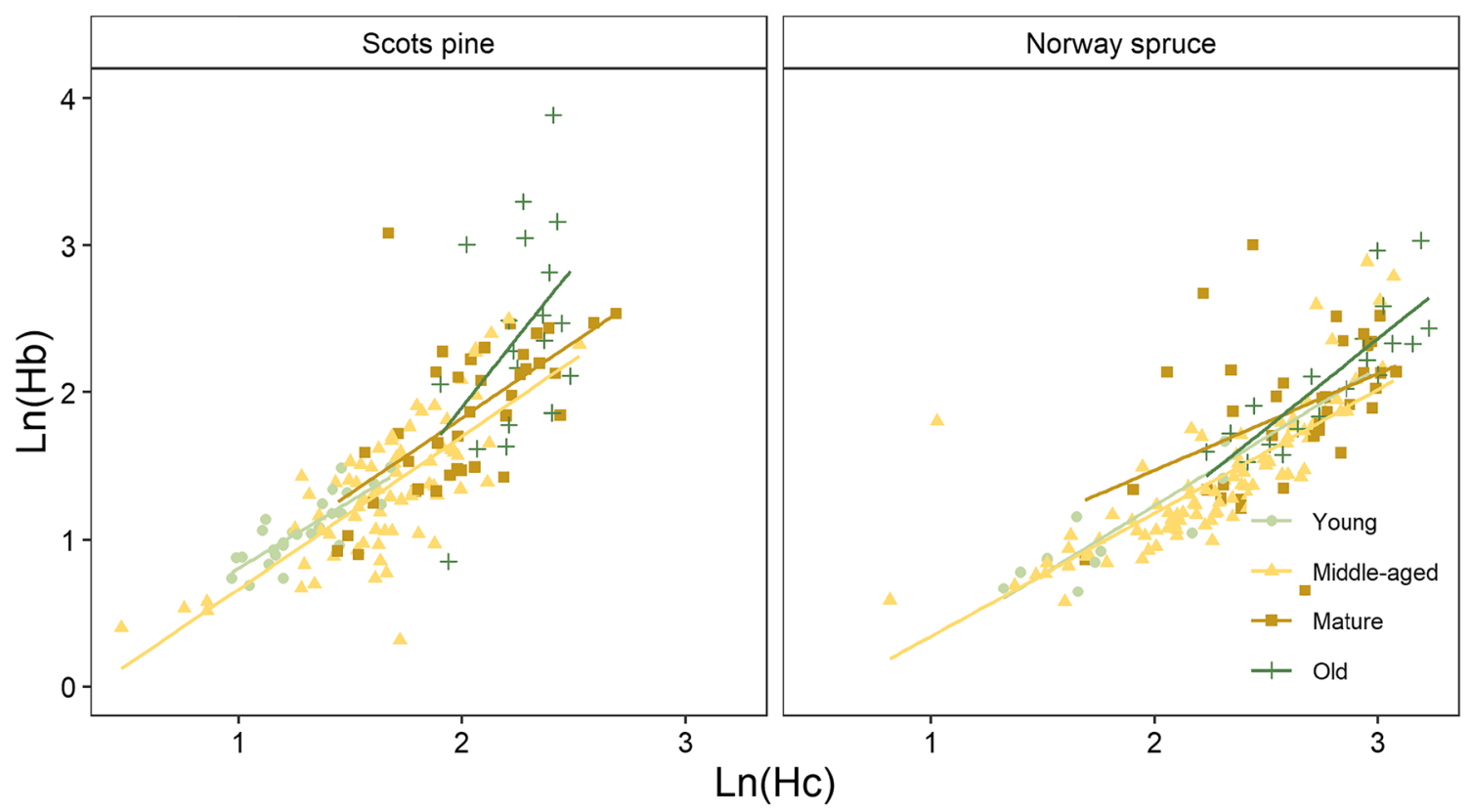

Fig. 6 Mean branch length as a function of crown length (in ln-transformation) in different age groups for Scots pine and Norway spruce

equations, to ignore the site-type effect in the subsequent age-dependence test.

\subsection{Age effect on biomass allocation and tree growth}

Our results on tree biomass in the age groups confirm the wellknown observation that with increasing total biomass (Table 2), the contribution of stem to total aboveground biomass increases considerably while that of branch and especially foliage decreases (Fig. 1). On the other hand, no statistically significant difference was found between the foliage biomass of the old and mature groups, although stem and branch biomasses were still increasing. This is partly due to the fact that stem and branch biomasses accumulate while foliage biomass turns over, such that allocation of growth to foliage may still be considerable in the old trees. On the other hand, previous studies have reported a steady increase of the fine-roots-to-foliage biomass ratio with age, which would constitute a notable sink of carbon away from aboveground growth (Vanninen et al. 1996).

Tree structure variables, such as tree height and crown length, show an expected development with age. Furthermore, the fact that the difference between the mature and old groups is relatively small corroborates our somewhat arbitrary choice of age limits for the groups, as declining height growth has been taken as an indication of ageing in trees. However, this does not necessarily mean that total growth is slowing down, but could be related to a loss of apical dominance and a simultaneous shift of vertical to lateral dimensional growth (Hann and Larsen 1991; Meinzer et al. 2011; Weiskittel et al. 2011). Indeed, the old trees have distinctively wider crowns (indicated by $H_{b}$ ) than trees in the mature group (Table 2).
In addition, we observed that the crown ratio significantly decreased with age; however, the old group showed a slightly albeit not significantly larger crown ratio (Table 2) than the mature group in both species. Previous studies have shown that crown ratio is strongly indicative of aboveground biomass proportions (Nilsson and Albrektson 1993; Mäkelä and Vanninen 1998; Ilomäki et al. 2003; Kantola and Mäkelä 2006; Mäkelä and Valentine 2006). Here, more scatter was found in the relationship between crown ratio and branch/foliage biomass proportion (Fig. 2). This is probably because older trees show more variability in crown width relative to crown length (Fig. 3), leading to variability in branch and foliage biomass.

\subsection{Age effects on slope parameters of hypothesis equations}

The pipe model ratio, i.e. the ratio of foliage mass $\left(W_{f}\right)$ to stem cross-sectional area at crown base $\left(A_{c}\right)$ (Table $\left.6, k=1\right), \eta_{s}$, was lower in the old than in the middle-aged or mature group in both species, although the difference was not significant in Norway spruce. As the original pipe model assumption is based on sapwood not total cross-sectional area at crown base, this result may simply indicate that the latter is not an adequate proxy of the former as trees grow older. Björklund (1999) presented evidence that heartwood formation starts in Scots pine rings on average at the ring age of 60 years. In old trees, height growth and crown rise have slowed down, such that the age of the stem at crown base could well be much more than 60 years. This suggests that the total cross-sectional area proxy becomes less accurate with increasing tree age. On the other hand, some studies indicate that heartwood formation starts even earlier in Norway spruce, and its 
crown rise is also slower than in Scots pine (Longuetaud et al. 2006), which would mean that there is already heartwood at Norway spruce crown base at an early age. This could reduce the age dependence of the relationship between sapwood area and total area at crown base in Norway spruce, rendering the pipe model parameter $\eta_{s}$ less age-dependent of age (Table 6).

Regarding the branch-related parameters, age dependence was detected in Norway spruce only. In accordance with previous studies (Kantola and Mäkelä 2004), the ratio of $A_{b}$ to $A_{c}$ (Table $6, k=2$ ), $\eta_{s} / \eta_{b}$, was found to be largest in the old group. This means that, all other things being equal, old trees would have more branch biomass for a given $A_{c}$ than younger trees. On the other hand, with a given $H_{b} \cdot A_{b}$, branch biomass in the old group was significantly smaller than in the other groups (smaller $\varphi_{b}$ ) (Table 6, $k=3$ ). Moreover, larger branch parameters $\left(\gamma_{b}, b\right)$ were found in the old group than those in younger stands (Table $6, k=4$ ). These results suggest that in old trees, branches taper faster or furcate less into successive forking branches than in younger trees. This can be explained by branch turnover: if branches live long, they are likely to break and lose distal twigs over time, thus reducing the form coefficient $\varphi_{b}$ (Table 6, $k=3$ ). Surprisingly, age dependence was not found for branch-related parameters in Scots pine. This may be related to the rate of crown rise and thus the length of crowns in the old trees: Scots pine as a light-demanding species sheds its branches more readily than the more shade-tolerant Norway spruce (Kellomäki and Oker-Blom 1981; Modrý et al. 2004). Crown shape therefore remains more constant in Scots pine, probably explaining the relative stability of the branch form coefficient $\varphi_{b}$ in Scots pine.

As for the stem form coefficients, age dependence was detected in both species in $\varphi_{c}$ but neither in $\varphi_{s}$. In Scots pine, $\varphi_{c}$ was significantly smaller in the old than in the mature group, denoting a steeper taper in the old trees inside the crown $\left(\operatorname{smaller} \varphi_{c}\right.$ ). This seems consistent with the above observation that in old Scots pine trees an increasing proportion of growth is directed horizontally to branch rather than stem growth. The bigger branches are at the lower part of the crown, and their growth will require respective stem diameter growth in the lower crown (Table 2). Although there is no obvious difference in stem and branch biomass proportion between the mature and old group, we can still observe a slightly larger proportion of branch biomass in trees of the old group. In contrast, in Norway spruce, $\varphi_{c}$ was significantly larger in the old group than in the mature or middle-aged group which suggests less tapering of stem inside the crown. As noted above, old Norway spruce crowns tend to be long, with shaded, less vigorously growing branches in the lower crown (Kantola and Mäkelä 2006). In light of the pipe model, this seems consistent with our result of a weaker taper in the crowns of the old trees.

In addition, no age dependence was detected in the relationship between $\varphi_{s}$ and $(1+r) / 2 r$ in both species, which indicates that $\varphi_{s}$ followed a prescribed dependence on crown ratio rather than tree age. This is consistent with previous findings that cross- sectional area at crown base depends on cross-sectional area at breast height and the distance from breast height to crown base (Long and Smith 1984).

Overall, the detected differences between old trees and the others seem realistic. As described above, most of them can be traced back to changes in the relationships between crown length and mean branch length, and the latter further to changes in crown shape with old age. In addition, old trees have less foliage mass with a given basal area at the crown base, probably due to more heartwood formation at the crown base. These changes are consistent with our general understanding of old-growth dynamics (Oliver and Larson, 1996). Furthermore, because the changes of growth habit are different in different species, so are the required parameter modifications. How this could most efficiently be taken into account in growth models applying PMT-based structure equations remains a challenge for our future work.

\section{Conclusion}

In conclusion, the PMT-based structure equations provided good estimates of tree biomass components, even when considered on average for the whole dataset. This suggests that tree structure is inherently very regular. However, many parameter changes are needed if the old trees are to be described more accurately. This poses a challenge for models utilising such structure equations, but also defines a necessary task for modelling if the models are to account realistically for changes in carbon allocation patterns in old trees. Furthermore, in order to obtain a more comprehensive understanding of age-related tree structure, we also need to extend the study to a wider coverage of site types, to explore the possible interaction between age and site quality for tree structure.

Acknowledgements Open access funding provided by University of Helsinki including Helsinki University Central Hospital. We would like to thank Xianglin Tian, Che Liu, Kourosh K Koupaei and Atte T Kumpu for the valuable comments on study development. We are thankful to Kenneth Quek for the language revision. We also appreciate the work by the field teams from Finnish Forest Research Institute (METLA) for collecting VAPU data.

Funding AM and FM were supported by The Academy of Finland Strategic Council project IBC-CARBON (grant no. 312559). AL has been also supported by the grant BiBiFe: Biogeochemical and biophysical feedbacks from forest harvesting to climate change (grant no. 325680) were provided by Academy of Finland. MH was supported by Chinese Scholarship Council (grant no. 201706510034).

Data availability The datasets analysed during the current study are available in the Zenodo repository, https://doi.org/10.5281/zenodo.3940310

\section{Compliance with ethical standards}

Conflicts of interest The authors declare that they have no conflict of interest. 


\section{Appendix 1. Sample trees in different age group by site type}

Table 7 Aboveground biomass of Scots pine and Norway spruce in different age groups by the site type, and their $F$ and $p$ values. The mean values (kg $\operatorname{tre}^{-1}$ ) and standard error were provided for each age group on relevant site type. $n=$ number of observations

\begin{tabular}{|c|c|c|c|c|c|c|}
\hline Site type & $n$ & $F$ & $p$ & 2 & 3 & 4 \\
\hline \multicolumn{7}{|l|}{ Scots pine } \\
\hline Young & 32 & 0.479 & 0.494 & NA & $14.019 \pm 3.801$ & $16.855 \pm 2.002$ \\
\hline Middle-aged & 72 & 14.51 & 0.001 & NA & $91.460 \pm 14.400$ & $41.857 \pm 5.909$ \\
\hline Mature & 38 & 4.456 & 0.042 & NA & $272.341 \pm 39.412$ & $183.792 \pm 22.016$ \\
\hline Old & 20 & 1.114 & 0.305 & NA & $513.19 \pm 9.015$ & $379.540 \pm 41.191$ \\
\hline \multicolumn{4}{|c|}{ Tree number on each site type } & NA & 44 & 118 \\
\hline \multicolumn{7}{|l|}{ Norway spruce } \\
\hline Young & 12 & 0.644 & 0.441 & $82.375 \pm 58.375$ & $14.911 \pm 1.531$ & NA \\
\hline Middle-aged & 95 & 7.854 & 0.006 & $135.238 \pm 23.888$ & $74.049 \pm 8.083$ & NA \\
\hline Mature & 37 & 3.722 & 0.062 & $291.679 \pm 26.650$ & $197.802 \pm 38.673$ & NA \\
\hline Old & 19 & 16.380 & 0.001 & $863.808 \pm 36.561$ & $531.252 \pm 49.037$ & NA \\
\hline \multicolumn{4}{|c|}{ Tree number on each site type } & 66 & 79 & NA \\
\hline
\end{tabular}

\section{Appendix 2. Branch wood and foliage biomass estimates}

The dry weight of branch $i$ on tree $k\left(w_{b k i}\right)$ was modelled as a function of branch diameter $\left(d_{k i}\right)$ :

$$
\begin{aligned}
\ln w_{b k i}(d)= & \ln A_{0}+A_{1}\left[\ln \left(d_{k i}\right)\right]^{0.22}+\ln a_{0 k}+a_{1 k}\left[\ln \left(d_{k i}\right)\right]^{0.22} \\
& +\ln e_{k i}
\end{aligned}
$$

where $A_{0}$ and $A_{1}$ are fixed parameters, while $a_{0 k}$ and $a_{1 k}$ are

Table 8 Parameter estimates of the branch woody biomass model and the foliage biomass model. Standard deviation (SD) and $p$ values of fixed parameters, variance of random parameter and residuals are given

\begin{tabular}{lllrll}
\hline Components & Species & Parameter & Estimate & SD & $p$ \\
\hline Branch wood & \multirow{2}{*}{ Scots pine } & $\ln A_{0}$ & -36.100 & 5.688 & 0.0000 \\
& & $A_{1}$ & 32.514 & 4.438 & 0.0000 \\
& \multirow{3}{*}{ Norway spruce } & $\ln A_{0}$ & -19.427 & 8.884 & 0.0000 \\
& & $A 1$ & 16.556 & 6.092 & 0.0000 \\
& \multirow{3}{*}{ Scotiage } & $\ln A_{0}$ & -1.277 & 0.088 & 0.0000 \\
& & $A_{1}$ & 2.357 & 0.032 & 0.0000 \\
& & $A_{2}$ & 2.861 & 0.137 & 0.0000 \\
& & $A_{3}$ & -1.458 & 0.135 & 0.0000 \\
& \multirow{4}{*}{ Norway spruce } & $\ln A_{0}$ & -1.106 & 0.112 & 0.0000 \\
& & $A 1$ & 2.210 & 0.041 & 0.0000 \\
& & $A 2$ & 5.573 & 0.168 & 0.0000 \\
& & $A 3$ & -4.207 & 0.170 & 0.0000 \\
\hline
\end{tabular}

random tree parameters with zero expectations. The total branch wood mass of each sample tree was determined by summing up the biomasses of individual living branches (Lehtonen et al. 2004b). For Norway spruce with height $>$ $10 \mathrm{~m}$, since the branches were measured every second metre from the treetop, total branch biomass was calculated by doubling the estimates.

Foliage mass of branch $i$ on tree $k\left(w_{k i}\right)$ was modelled as a function of branch diameter $\left(d_{k i}\right)$ and the relative height of the branch in the crown $\left(h r_{k i}\right)$ :

$$
\begin{aligned}
\ln w_{k i}(d, \mathrm{hr})= & \ln A_{0}+A_{1} \ln \left(d_{\mathrm{ki}}\right)+A_{2}\left(\mathrm{hr}_{\mathrm{ki}}\right)+A_{3}\left(\mathrm{hr}_{\mathrm{ki}}^{2}\right) \\
& +\ln a_{0 k}+a_{1 k} \ln \left(d_{\mathrm{ki}}\right)+\ln e_{\mathrm{ki}}
\end{aligned}
$$

where $A_{0}, A_{1}, A_{2}$ and $A_{3}$ are fixed parameters and $a_{0 k}$ and $a_{1 k}$

Table 9 Effect of site type on hypothesis equations in Scots pine and Norway spruce. The $p$ values and chi square $\left(\chi^{2}\right)$ are listed

\begin{tabular}{lllllll}
\hline$x^{k}$ & $y^{k}$ & \multicolumn{2}{l}{ Scots pine (162) } & & \multicolumn{2}{l}{ Norway spruce (163) } \\
& & $p$ & $\chi^{2}$ & & $p$ & $\chi^{2}$ \\
\hline$A_{c}$ & $W_{f}$ & 0.841 & 0.039 & & 0.053 & 3.746 \\
$A_{c}$ & $A_{b}$ & 0.348 & 0.880 & & 0.288 & 1.125 \\
$\rho_{b} H_{b} A_{b}$ & $W_{b}$ & 0.145 & 2.117 & & 0.787 & 0.073 \\
$\ln H_{c}$ & $\ln H_{b}$ & 0.790 & 0.070 & & 0.373 & 0.793 \\
$H_{c} A_{c}$ & $V_{c}$ & 0.157 & 1.997 & & 0.183 & 1.772 \\
$(1+r) / 2 r$ & $\varphi_{s}$ & 0.198 & 1.650 & & 0.969 & 0.001 \\
\hline
\end{tabular}


are random tree parameters with zero expectations. The total foliage mass of each sample tree was calculated by summing up the foliage biomass from every living branch (Lehtonen 2005). For Norway spruce with height $>10 \mathrm{~m}$, since the branches were measured every second metre from the treetop, total foliage biomass was calculated by doubling the estimates.

Open Access This article is licensed under a Creative Commons Attribution 4.0 International License, which permits use, sharing, adaptation, distribution and reproduction in any medium or format, as long as you give appropriate credit to the original author(s) and the source, provide a link to the Creative Commons licence, and indicate if changes were made. The images or other third party material in this article are included in the article's Creative Commons licence, unless indicated otherwise in a credit line to the material. If material is not included in the article's Creative Commons licence and your intended use is not permitted by statutory regulation or exceeds the permitted use, you will need to obtain permission directly from the copyright holder. To view a copy of this licence, visit http://creativecommons.org/licenses/by/4.0/.

\section{References}

Bates D, Mächler M, Bolker B, Walker S (2014) Fitting linear mixedeffects models using lme4. https://doi.org/10.18637/jss.v067.i015

Berninger F, Coll L, Vanninen P, Mäkelä A, Palmroth S, Nikinmaa E (2005) Effects of tree size and position on pipe model ratios in Scots pine. Can J For Res 35:1294-1304. https://doi.org/10.1139/x05-055

Björklund L (1999) Identifying heartwood-rich stands or stems of Pinus sylvestris by using inventory data. Silva Fennica 33:119-129

Busing R, Garman S (2002) Promoting old-growth characteristics and long-term wood production in Douglas-fir forests. For Ecol Manag 160:161-175

Cajander AK (1949) Forest types and their significance

Cintas O, Berndes G, Hansson J, Poudel BC, Bergh J, Börjesson P, Egnell G, Lundmark T, Nordin A (2017) The potential role of forest management in Swedish scenarios towards climate neutrality by mid century. For Ecol Manag 383:73-84

Franklin O, Johansson J, Dewar RC, Dieckmann U, McMurtrie RE, Brannstrom A, Dybzinski R (2012) Modeling carbon allocation in trees: a search for principles. Tree Physiol 32:648-666. https://doi. org/10.1093/treephys/tpr138

Gustafson EJ (2007) Relative influence of the components of timber harvest strategies on landscape pattern. For Sci 53:556-561. https://doi.org/10.1093/forestscience/53.5.556

Hann DW, DR Larsen (1991) Diameter growth equations for fourteen tree species in southwest Oregon

Horáček P, Fajstavr M, Stojanović M (2017) The variability of wood density and compression strength of Norway spruce (Picea abies/ L./Karst.) within the stem. Beskydy 10:17-26. https://doi.org/10. 11118/beskyd201710010017

Hu M, Lehtonen A, Minunno F, Mäkelä A (2020) Data for "age effect on tree structure and biomass allocation in Scots pine (Pinus sylvestris L.) and Norway spruce (Picea abies [L.] Karst.)". [Data set]. Zenodo repository. V1. https://doi.org/10.5281/zenodo.3940310

Ilomäki S, Nikinmaa E, Mäkelä A (2003) Crown rise due to competition drives biomass allocation in silver birch. Can J For Res 33:23952404
Inagaki Y, Nakanishi A, Tange T (2019) A simple method for leaf and branch biomass estimation in Japanese cedar plantations. Trees 34: 349-356. https://doi.org/10.1007/s00468-019-01920-8

Ise T, Litton CM, Giardina CP, Ito A (2010) Comparison of modeling approaches for carbon partitioning: impact on estimates of global net primary production and equilibrium biomass of woody vegetation from MODIS GPP. J Geophys Res 115

Kantola A, Mäkelä A (2004) Crown development in Norway spruce [Picea abies (L.) Karst.]. Trees 18:408-421

Kantola A, Mäkelä A (2006) Development of biomass proportions in Norway spruce (Picea abies [L.] Karst.). Trees 20:111-121

Kellomäki S, P Oker-Blom (1981) Specific needle area of Scots pine and its dependence on light conditions inside the canopy

Lämås T, Fries C (1995) Emergence of a biodiversity concept in Swedish forest policy. Water Air Soil Pollut 82:57-66

Landsberg J, Waring R (1997) A generalised model of forest productivity using simplified concepts of radiation-use efficiency, carbon balance and partitioning. For Ecol Manag 95:209-228

Lasch P, Badeck F-W, Suckow F, Lindner M, Mohr P (2005) Modelbased analysis of management alternatives at stand and regional level in Brandenburg (Germany). For Ecol Manag 207:59-74. https://doi.org/10.1016/j.foreco.2004.10.034

Lehtonen A (2005) Estimating foliage biomass in Scots pine (Pinus sylvestris) and Norway spruce (Picea abies) plots. Tree Physiol 25: 803-811. https://doi.org/10.1093/treephys/25.7.803

Lehtonen A, Heikkinen J, Petersson H, Ťupek B, Liski E, Mäkelä A (2019) Scots pine and Norway spruce foliage biomass in Finland and Sweden - testing traditional models versus the pipe model theory. Can J For Res 50:146-154. https://doi.org/10.1139/cjfr-20190211

Lehtonen A, Mäkipää R, Heikkinen J, Sievänen R, Liski J (2004a) Biomass expansion factors (BEFs) for scots pine, Norway spruce and birch according to stand age for boreal forests. For Ecol Manag 188:211-224. https://doi.org/10.1016/j.foreco.2003.07.008

Lehtonen A, Sievänen R, Mäkelä A, Mäkipää R, Korhonen KT, Hokkanen T (2004b) Potential litterfall of Scots pine branches in southern Finland. Ecol Model 180:305-315. https://doi.org/10. 1016/j.ecolmodel.2004.04.024

Lin F, Haseman J (1978) An evaluation of some nonparametric multiple comparison procedures by Monte Carlo methods. Commu Statistics-Simulation Comput 7:117-128

Long JN, Smith FW (1984) Relation between size and density in developing stands: a description and possible mechanisms. For Ecol Manag 7:191-206

Longuetaud F, Mothe F, Leban J-M, Mäkelä A (2006) Picea abies sapwood width: variations within and between trees. Scand J For Res 21:41-53

Luyssaert S, Schulze ED, Borner A, Knohl A, Hessenmoller D, Law BE, Ciais P, Grace J (2008) Old-growth forests as global carbon sinks. Nature 455:213-215. https://doi.org/10.1038/nature07276

Mäkelä A (1986) Implications of the pipe model-theory on dry-matter partitioning and height growth in trees. J Theor Biol 123:103-120. https://doi.org/10.1016/S0022-5193(86)80238-7

Mäkelä A (1997) A carbon balance model of growth and self-pruning in trees based on structural relationships. For Sci 43:7-24. https://doi. org/10.1093/forestscience/43.1.7

Mäkelä A, Valentine HT (2006) Crown ratio influences allometric scaling in trees. Ecology 87:2967-2972. https://doi.org/10.1890/00129658(2006)87[2967:Criasi]2.0.Co;2

Mäkelä A, Vanninen P (1998) Impacts of size and competition on tree form and distribution of aboveground biomass in Scots pine. Can J For Res 28:216-227

McGilchrist C, Yau K (1995) The derivation of BLUP, ML, REML estimation methods for generalised linear mixed models. Commu Statis-Theory Methods Ecol Evol 24:2963-2980 
Medhurst J, Battaglia M, Cherry M (1999) Allometric relationships for Eucalyptus nitens (Deane and Maiden) Maiden plantations. Trees 14:91-101

Meinzer FC, Lachenbruch B, Dawson TE (2011) Size-and age-related changes in tree structure and function. Springer Science \& Business Media, Berlin

Minunno F, Peltoniemi M, Härkönen S, Kalliokoski T, Makinen H, Mäkelä A (2019) Bayesian calibration of a carbon balance model PREBAS using data from permanent growth experiments and national forest inventory. For Ecol Manag 440:208-257. https://doi. org/10.1016/j.foreco.2019.02.041

Modrý M, Hubený D, Rejšek K (2004) Differential response of naturally regenerated European shade tolerant tree species to soil type and light availability. For Ecol Manag 188:185-195

Monserud RA, Marshall JD (1999) Allometric crown relations in three northern Idaho conifer species. Can J For Res 29:521-535

Nilsson U, Albrektson A (1993) Productivity of needles and allocation of growth in young scots pine trees of different competitive status. For Ecol Manag 62:173-187

Oliver CD, BC Larson, C Oliver (1996) Forest stand dynamics, Wiley New York

Purves D, Pacala S (2008) Predictive models of forest dynamics. Science 320:1452-1453. https://doi.org/10.1126/science.1155359

Repola J (2009) Biomass equations for Scots pine and Norway spruce in Finland

Sattler DF, Comeau PG (2015) Crown allometry and application of the pipe model theory to white spruce (Picea glauca (Moench) Voss) and aspen (Populus tremuloides Michx.) in the western boreal forest of Canada. Can J For Res 46:262-273

Shapiro SS, Wilk MB (1965) An analysis of variance test for normality (complete samples). Biometrika 52:591-611

Shelburne V, Hedden R, Allen R (1993) The effect of site, stand density, and sapwood permeability on the relationship between leaf area and sapwood area in loblolly pine (Pinus taeda L.). For Ecol Manag 58: 193-209

Shinozaki K, Yoda K, Hozumi K, Kira T (1964a) A quantitative analysis of plant form-the pipe model theory: I. Basic analyses. Japanese J. Ecol. 14:97-105
Shinozaki K, Yoda K, Hozumi K, Kira T (1964b) A quantitative analysis of plant form-the pipe model theory: II. Further evidence of the theory and its application in forest ecology. Japanese J. Ecol. 14: 133-139

Triviño M, Pohjanmies T, Mazziotta A, Juutinen A, Podkopaev D, Le Tortorec E, Mönkkönen M, Mori A (2017) Optimizing management to enhance multifunctionality in a boreal forest landscape. J Appl Ecol 54:61-70. https://doi.org/10.1111/1365-2664.12790

Valentine HT (1985) Tree-growth models: derivations employing the pipe-model theory. J Theor Biol 117:579-585

Valentine HT, Baldwin VC Jr, Gregoire TG, Burkhart HE (1994) Surrogates for foliar dry matter in loblolly pine. For Sci 40:576585. https://doi.org/10.1093/forestscience/40.3.576

Valentine HT, Mäkelä A (2005) Bridging process-based and empirical approaches to modeling tree growth. Tree Physiol 25:769-779

Vanninen P, Mäkelä A (2000) Needle and stem wood production in Scots pine (Pinus sylvestris) trees of different age, size and competitive status. Tree Physiol 20:527-533

Vanninen P, Mäkelä A (2005) Carbon budget for Scots pine trees: effects of size, competition and site fertility on growth allocation and production. Tree Physiol 25:17-30. https://doi.org/10.1093/treephys/ 25.1.17

Vanninen P, Ylitalo H, Sievänen R, Mäkelä A (1996) Effects of age and site quality on the distribution of biomass in Scots pine (Pinus sylvestris L.). Trees 10:231-238

Weiskittel AR, Hann DW, Kershaw JA Jr, Vanclay JK (2011) Forest growth and yield modeling. John Wiley \& Sons

Williams LJ, Abdi H (2010) Fisher's least significant difference (LSD) test. In: Encyclopedia of research design, vol 218, pp 840-853

Yli-Kojola H, A Ahola (1995) Pysyvien koealojen 3. mittaus 1995. Maastotyön ohjeet. Metsäntutkimuslaitos, Helsingin tutkimuskeskus. Valtakunnan metsien inventointi. Moniste

Zianis D, Muukkonen P, Mäkipää R, Mencuccini M (2005) Biomass and stem volume equations for tree species in Europe. Silva Fennica Monographs

Publisher's note Springer Nature remains neutral with regard to jurisdictional claims in published maps and institutional affiliations. 